\title{
Routine collection of sexual orientation and gender identity data: a mixed-methods study
}

\author{
Andrew D. Pinto MD MSc, Tatiana Aratangy PhD, Alex Abramovich PhD, Kim Devotta MA, Rosane Nisenbaum \\ PhD, Ri Wang MMath, Tara Kiran MD MSc
}

Cite as: CMAJ 2019 January 21;191:E63-8. doi: 10.1503/cmaj.180839

See related article at www.cmaj.ca/lookup/doi/10.1503/cmaj.190011

\begin{abstract}
BACKGROUND: Sexual orientation and gender identity are key social determinants of health, but data on these characteristics are rarely routinely collected. We examined patients' reactions to being asked routinely about their sexual orientation and gender identity, and compared answers to the gender identity question against other data in the medical chart on gender identity.
\end{abstract}

METHODS: We analyzed data on any patient who answered at least 1 question on a routinely administered sociodemographic survey between Dec. 1, 2013, and Mar. 31, 2016. We also conducted semi- structured interviews with 27 patients after survey completion.

RESULTS: The survey was offered to 15221 patients and 14247 (93.6\%) responded to at least 1 of the sociodemographic survey questions. Most respondents answered the sexual orientation (90.6\%) and gender identity $(96.1 \%)$ questions. Many patients who had been classified as transgender or gender diverse in their medical chart did not self-identify as transgender, but rather selected female (22.9\%) or male (15.4\%). In the semistructured interviews, many patients expressed appreciation at the variety of options available, although some did not see their identities reflected in the options and some felt uncomfortable answering the questions.

INTERPRETATION: We found a high response rate to questions about sexual orientation and gender identity. Fitting with other research, we suggest using a 2-part question to explore gender identity. Future research should evaluate the acceptability and feasibility of administering these questions in a variety of care settings. These data can help organizations identify health inequities related to sexual orientation and gender identity.
$\mathrm{H}$ ealth organizations have begun to explore ways to address social determinants of health to improve care and reduce health inequities. ${ }^{1-6}$ One barrier is insufficient individual-level data on social determinants of health. ${ }^{7-10}$ Gender identity and sexual orientation are important social determinants, ${ }^{11-13}$ but such data are rarely routinely collected by health care organizations. ${ }^{14-16}$

Gender identity is a predictor of health outcomes and can affect access to health care. ${ }^{17,18}$ Transgender and gender-diverse individuals ${ }^{19-22}$ (Box 1 ) consistently report negative experiences in health care related to their gender identity. ${ }^{23-25}$ Sexual orientation is also an important predictor of health status and access to health care. ${ }^{15}$ For example, women who identify as lesbian have lower rates of cervical cancer screening than those who identify as heterosexual ${ }^{26,27}$ and bisexual people report more unmet health needs than heterosexual people. ${ }^{26}$

Information on gender identity is particularly crucial to the care of transgender and gender-diverse individuals, and whether to disclose is not always a choice. ${ }^{15}$ Being comfortable with disclosing gender identity and sexual orientation can be an indica- tor of trust and can influence the quality and effectiveness of care. ${ }^{15,28}$ Certain health interventions, such as human papillomavirus vaccination or HIV pre-exposure prophylaxis, are focused on specific groups based on sexual orientation. ${ }^{29}$

Recently, the Canadian Institute for Health Information suggested that data on gender identity be collected as 1 of 5 domains to identify health inequalities. ${ }^{30}$ It remains unclear how Canadian patients react to being asked routinely about sexual orientation and gender identity, or what responses such questions would generate. The objective of this study was to examine patients' reactions to routinely being asked about their sexual orientation and gender identity in a primary health care setting. We also compared answers to the gender identity question against other data on gender identity in the medical chart.

\section{Methods}

\section{Setting and context}

In 2011, health organizations in Toronto developed a sociodemographic survey to identify inequities at a system level, by reviewing 
the literature and through a consensus process. ${ }^{31,32}$ The sexual orientation and gender identity questions (Figure 1) appear in the middle of the survey (Appendix 1, available at www.cmaj.ca/ lookup/suppl/doi:10.1503/cmaj.180839/-/DC1). A preamble notes that the purpose of data collection is to improve access and quality of care and to identify health inequities, that participation is voluntary, and that the information will be kept safely in the medical chart. The survey was pilot tested at 4 institutions, including the St. Michael's Hospital Academic Family Health Team, ${ }^{31,32}$ but the questions have not been validated.

The St. Michael's Hospital Academic Family Health Team is a large primary care organization with 6 sites in downtown Toronto, Canada. About 44000 enrolled patients are served by 130 health professionals, including 75 physicians. Patients are diverse in terms of income, citizenship status, race, sexual orientation and gender identity. Since 2013, the St. Michael's Hospital Academic Family Health Team has routinely administered the

\section{Box 1: Terms used to describe gender identity and} sexual orientation ${ }^{19-22}$

- Gender identity refers to a person's subjective experience of their own gender. It is a deep, internal feeling of whether they identify as female, male, genderqueer or anywhere along the gender spectrum. A person's gender identity may be the same as or different from their sex assigned at birth and is separate from their sexual orientation.

- Transgender or trans is an umbrella term used to describe people whose gender identity does not match with the sex they were assigned at birth. A person who was assigned female at birth but identifies as a man is a trans man or transgender man. A person who was assigned male at birth but identifies as a woman is a trans woman or transgender woman.

- Gender diverse refers to a wide range of gender identities and expressions that challenge gender norms, and can include nonbinary, genderqueer and genderfluid.

- Intersex refers to people whose reproductive systems, chromosomes or hormones are not easily characterized as male or female. Intersex people do not always identify as intersex, and may identify as male, female, trans or nonbinary.

- Sexual orientation, increasingly referred to as "sexual identity," is the emotional, physical, romantic, sexual and spiritual attraction, desire or affection for another person, and people define their sexual orientation in various ways.

- Heterosexual or straight refers to a person who is mainly attracted to people of the opposite sex or gender identity.

- Gay refers to a person who is attracted mainly to people of the same sex or gender identity. This term is used by both men and women.

- Lesbian refers to a woman whose primary sexual and romantic attraction is toward other women.

- Bisexual refers to a person who is sexually and romantically attracted to those of the same sex or gender identity and those of another sex or gender identity.

- Two-spirit is an Indigenous person who identifies with both a male and female spirit. This identity is culturally specific to people of Indigenous ancestry and can also refer to sexual orientation.

- Queer refers to a person who does not identify with binary terms that describe sexual, gender and sociopolitical constructed identities. survey to all patients in waiting rooms. Electronic and hard-copy versions are offered to patients at registration. Electronically entered data are automatically added to the electronic medical record; staff manually enter data collected on paper. Once in the electronic medical record, the data are visible to health providers as a string of text in the progress notes.

\section{Study design}

We applied both quantitative and qualitative methods. An advisory group supported this study, composed of patients, representatives from the local health authority, the provincial quality improvement agency, other hospitals and local community health centres, the Association of Family Health Teams of Ontario and the Canadian Institute for Health Information. This group provided feedback on our study design, assisted with data interpretation and provided thoughts on the implications of our findings at a system level.

\section{Quantitative methods}

We completed a descriptive analysis of responses to the survey questions on sexual orientation and gender identity for patients who completed at least 1 question on the survey between Dec. 1, 2013, and Mar. 31, 2016. We compared patients' gender identity as documented in the chart against self-reported gender identity from the survey responses. Gender identity as documented in the chart was ascertained in a 2-step process. First, if patients had an International Classification of Diseases, 9th Edition (ICD) code for gender dysphoria (ICD-9 302.85) in their chart, they were categorized as "transgender or gender diverse." The ICD code was added to the chart in 2016 after a manual audit and validation with the most responsible provider, as described elsewhere. ${ }^{33}$ Second, all

\section{What is your gender? Check ALL that apply: \\ Female \\ Male \\ Trans - female to male \\ $\square$ Trans - male to female \\ Intersex \\ Other \\ Prefer not to answer \\ Do not know}

What is your sexual orientation? Check 1 only:

Heterosexual (straight, male/female relationships)

Gay

Lesbian

Bisexual

2-spirit

Queer

Other

Prefer not to answer

Do not know

Figure 1: Questions about gender identity and sexual orientation used in the St. Michael's Hospital Academic Family Health Team. 
remaining patients were categorized as "male" or "female" based on the sex designation on the provincial health insurance card.

\section{Statistical analysis}

We used the $\chi^{2}$ test to compare those with and without the ICD code for gender dysphoria for the proportion of patients who reported "prefer not to answer" or "don't know" and the proportion who did not answer the survey question on gender identity. Survey responses, ICD coding and sex designation were extracted from the electronic medical record at our practice by our specialist in this area. All analyses were completed using R (version 3.4.0).

\section{Qualitative methods}

Research staff, including 1 member of the study team (K.D.), conducted 27 semistructured, individual interviews, using verbal probing cognitive interviewing techniques (patient interview guide available in Appendix 2, at www.cmaj.ca/lookup/suppl/ doi:10.1503/cmaj.180839/-/DC1). ${ }^{34}$ We recruited patients in person in clinic waiting rooms, shortly after they had completed the survey, between May 2016 and July 2016; these patients represent a convenience sample. We interviewed patients to understand their thought processes about, reactions to and experience of the survey questions. We conducted the interviews, which lasted on average 29 minutes, in a private space. We collected patient demographics to ensure variability in the participants interviewed. We conducted the interviews in English, and patients were required to have sufficient fluency to complete the consent process and understand all questions. We audiorecorded and transcribed the interviews verbatim.

\section{Data analysis}

We analyzed the transcripts using content analysis ${ }^{35}$ with NVivo 9 (QSR International). A team of 5 coders, including K.D. and T.A., independently reviewed and coded a small number of transcripts ( $n=4$, based on maximum variability in the number and type of issues that they identified with the survey). We defined cognitive interviewing codes (e.g., question comprehension, response mapping) a priori. ${ }^{36}$ As a group, the 5 coders and the 2 principal investigators (A.P. and T.K.) reviewed and defined the codes through consensus, leading to an initial code book. We completed the coding of the remaining transcripts in 2 rounds, with revision of codes between rounds, and calculated the inter-rater reliability as $95.3 \%$.

The entire study team reviewed the coded data, areas of consensus and contradictory observations and presented them to the advisory group. We conducted the interviews, analysis and discussion of findings iteratively until we achieved saturation in key themes.

\section{Ethics approval}

The St. Michael's Hospital Research Ethics Board approved a study protocol for the qualitative component. Institutional authorities at St. Michael's Hospital formally reviewed a protocol for the quantitative component.

\section{Results}

During the study period, 15221 patients were offered the survey and $14247(93.6 \%)$ responded to at least 1 of the questions. Most patients answered questions about gender identity $(96.1 \%)$ and sexual orientation (90.6\%) (Table 1, Table 2). Of these, $103(0.7 \%)$ patients chose a gender identity on the survey that was not congruent with the sex listed on their health card but did not have an ICD code on their chart for gender dysphoria. An additional 33 $(0.2 \%)$ selected transgender, but similarly did not have an ICD code for gender dysphoria on their chart.

Of the 175 patients who had an ICD code for gender dysphoria on their chart and who responded to the gender identity question,

Table 1: Comparison between self-reported gender identity disclosed in the

sociodemographic survey versus information from the patient chart*

\begin{tabular}{|c|c|c|c|c|}
\hline \multirow[b]{2}{*}{$\begin{array}{l}\text { Self-reported gender identity } \\
\text { disclosed in the survey }\end{array}$} & \multicolumn{4}{|c|}{ Information from the patient chart } \\
\hline & $\begin{array}{l}\text { Female, } \\
n(\%)\end{array}$ & Male, $n(\%)$ & $\begin{array}{c}\text { Transgender } \\
\text { or gender- } \\
\text { diverse, } † \\
n(\%)\end{array}$ & Total, $n(\%)$ \\
\hline Female & 7759 (95.7) & $72(1.2)$ & $40(22.9)$ & $7871(55.2)$ \\
\hline Male & $31(0.4)$ & $5629(94.3)$ & $27(15.4)$ & $5687(39.9)$ \\
\hline Transgender, intersex or other $\ddagger$ & $23(0.3)$ & $10(0.2)$ & $95(54.3)$ & $128(0.9)$ \\
\hline $\begin{array}{l}\text { Prefer not to answer, don't know } \\
\text { or no answer§ }\end{array}$ & $292(3.6)$ & $256(4.3)$ & $13(7.4)$ & $561(3.9)$ \\
\hline Total & 8105 & 5967 & 175 & 14247 \\
\hline \multicolumn{5}{|c|}{$\begin{array}{l}\text { *Counts smaller than } 5 \text { have been suppressed to reduce the risk of participant reidentification. } \\
\text { tPatients who had an International Classification of Diseases, 9th Edition code for gender dysphoria (ICD-9 302.85) on their } \\
\text { chart, added after a manual audit and validation with the most responsible provider. } \\
\text { fTransgender, intersex and other response options are not equivalent, but were combined to avoid disclosing cell counts } \\
\text { smaller than 5. The transgender category was much larger than all the other categories. } \\
\text { \$"Prefer not to answer," "don't know" and "no answer" response options were combined to avoid disclosing cell counts } \\
\text { smaller than 5. The "prefer not to answer" category was much larger than the "don't know" category. The "no answer" data } \\
\text { category includes respondents who started the questionnaire and did not finish it, but not necessarily because of the gender } \\
\text { identity question. }\end{array}$} \\
\hline
\end{tabular}


Table 2: Self-reported sexual orientation

disclosed in the sociodemographic survey

\section{Self-reported sexual orientation}

Heterosexual (straight)

Gay

Lesbian

Bisexual

2-spirited

Queer

Other

Don't know

Prefer not to answer

No answer ${ }^{\star}$

Total

"The "no answer" data category includes respondents who started the questionnaire and did not finish it, but not necessarily because of the sexual orientation question.

$40(22.9 \%)$ selected "female" as their gender identity and 27 (15.4\%) selected "male" (Table 1). Compared with other patients, those with an ICD code for gender dysphoria on their chart were more likely to select "prefer not to answer" or "don't know" (5.7\% v. 1.1\%, $p<0.01)$ and more likely to select "other" ( $2.9 \%$ v. $0.04 \%, p<0.01)$ when responding to the question on gender identity.

Twenty-seven patients were interviewed during the study. They were diverse in age, gender identity, education level, preferred language, immigration status and self-rated health (Appendix 3, available at www.cmaj.ca/lookup/suppl/doi:10.1503/cmaj.180839/-/ DC1). Several key themes emerged through the analysis. First, many patients said they appreciated the variety of options available for both the sexual orientation and gender identity questions. Unprompted, several patients reported that having diverse options created a positive impression of the health organization, which was perceived as an inclusive organization welcoming of lesbian, gay, bisexual, transgender, queer and 2-spirited (LGBTQ2S) individuals. Many patients with a variety of sexual orientations and gender identities wanted to know more about the meaning of the various options provided, and the questions sparked curiosity about sexual and gender diversity.

Second, some patients felt uncomfortable answering these questions. Some LGBTQ2S patients reported that answering the questions on sexual orientation and gender identity made them uncomfortable because these questions brought previous experiences of discrimination to the surface. Regarding the question on sexual orientation, 1 participant noted, "I'm trying to break free from what l've dealt with my whole life from my family ... the persecution of gays, and that whole history ... so it was difficult just for me personally to answer it. I made it through it, and answered it as honestly [as] I could. But [it was] still difficult, just because of what l've gone through and what l've had to hide in a sense." A small number of cisgender and heterosexual patients interviewed expressed discomfort with the response options provided, often relating their feelings to having been raised in environments not tolerant of diversity in gender identity and sexual orientation. One patient noted, "[The sexual orientation question -] it's just uncomfortable for me. (...) I grew up in a family that ... you're heterosexual and that's it."

Third, despite the variety of responses provided, some patients did not see their identities reflected in the options. The term "bi-flexible" was suggested as a response option for the sexual orientation question. Patients suggested adding a broader term, such as "gender nonbinary" as a gender identity response option. The gender identity question also did not include "2-spirited," although it was included in the question on sexual orientation. Adding an open-ended field as a way to capture specificity instead of trying to label all identities and orientations was also suggested for both questions. Fitting themselves into a specific category was difficult for patients who had recently come out as trans or were currently transitioning. "I' $m$ a trans woman, so I just don't know where I fall in there. Most of my life I went the way I was supposed to go, but now I'm coming out as my trans woman self. I left [the question] blank." Some patients were uncertain of the definition of the term "trans" and whether it referred to individuals who had socially or medically transitioned, or neither, or who had a gender identity that differed from the sex they were assigned at birth. One participant noted that since the data were being collected in a medical setting, she assumed a more clinical definition of the term. "I realized after I had put 'trans' that within a medical setting, it tends to see trans identity as a, as a very medical phenomena. In terms of the physical attributes of like and the sexual reproduction aspects and that's not like really my kind of association with terms."

\section{Interpretation}

We found a high response rate to questions on sexual orientation and gender identity when posed to patients in a primary care setting on a routinely administered survey in the waiting room. The response rate was lower among those who were identified as transgender or gender diverse in their medical chart. From the qualitative component of the study, the diversity of response options reflected positively on the institution. Despite the number of options provided, some LGBTQ2S individuals did not find an option that represented their identity, and some did not feel comfortable responding to these questions. Similar to other studies, ${ }^{15,18,37}$ patients who were identified as transgender or gender diverse in their medical chart did not selfidentify as transgender, but rather selected "female" or "male."

Previous work has shown that patients would feel comfortable answering questions about sexual orientation and gender identity in health settings. ${ }^{28}$ In a sample of 101 transgender patients from across the United States, $89 \%$ agreed that it was important for their primary care provider to know their gender identity, and $83 \%-86 \%$ were willing to disclose this via an electronic form at a computer kiosk. ${ }^{38}$ In a US online survey of 1516 patients with diverse sexual orientations, only $10 \%$ reported they would decline to disclose their sexual orientation in an emergency department. ${ }^{39} \mathrm{~A}$ recent review of perspectives on answering questions about sexual orientation and gender 
identity concluded that in general, people are willing to disclose this information and see it is relevant to their health. ${ }^{40}$

\section{Limitations}

Although we report findings from one of the largest primary care centres in Canada that is routinely collecting robust sociodemographic data, our findings are limited in that they are based on the experience of a single institution in an urban setting. The context in which such questions are presented to patients will influence their acceptability and the feasibility of collecting such data, ${ }^{15,41}$ and health organizations in other settings and those without a history of serving LGBTQ2S patients may have lower response rates. In our setting, patients are rostered to a specific physician and typically know who they will see.

Our study did not explore how patient comfort is influenced by their relationship with the patient's provider, or the sexual orientation and gender identity of their provider. Other studies have suggested this is important ${ }^{39.41}$ and these data could have helped explain why some patients selected "prefer not to answer," suggesting they did not feel safe in disclosing. Further research is required to explore whether patients selected "don't know" or "other" because they are exploring their sexual orientation and gender identity, or are transitioning, or simply did not prefer the options provided.

Finally, we leveraged our past efforts to identify patients with gender dysphoria based on a search of electronic medical records and a manual audit, but this method is imperfect owing to variable disclosure and documentation, potentially underestimating the size of this population in our setting. We found that less than $1 \%$ disclosed a gender identity on the survey that was incongruent with their health card, or chose "transgender" but did not have the diagnosis of gender dysphoria in their electronic medical record.

\section{Conclusion}

Our findings can inform Canadian health care organizations that wish to characterize their patients through routine collection of sociodemographic data. We suggest that questions on sexual orientation and gender identity include a variety of response options with definitions. In addition to prespecified options, "Identity not listed (please specify)" could be included. ${ }^{37}$ In alignment with a recent report from the Canadian Institute for Health Information, ${ }^{30}$ our findings support a 2-part gender identity question in which patients are asked about their sex assigned at birth (male or female), followed by their current gender identity. ${ }^{42}$ Organizations must set the stage for asking these questions, including training staff, stating how the data will be used and ensuring the clinic is a LGBTQ2S-positive and -inclusive space. ${ }^{41}$

Further research is required in a variety of Canadian and international settings in consultation with LGBTQ2S communities. ${ }^{43}$ Such work could result in a standard approach to implementation, data extraction and analysis. Research is also required on how data collection can affect awareness and acceptance of diverse sexual and gender identities. ${ }^{44}$ Data collection can contribute to evolving norms in Canadian society regarding sexual orientation and gender identity, make health settings welcoming to LGBTQ2S individuals and build awareness of the specific health needs of LGBTQ2S patients.

\section{References}

1. Social determinants of health - What doctors can do. London (UK): British Medical Association; 2011.

2. Health care in Canada: What makes us sick? - Canadian Medical Association town hall report [report]. Ottawa: Canadian Medical Association; July 2013. Available: www.cma.ca/Assets/assets-library/document/fr/advocacy/What-makes-us-sick_ en.pdf (accessed 2018 Oct. 6).

3. Health care transformation in Canada - physicians and health equity: opportunities in practice. Ottawa: Canadian Medical Association; 2013.

4. Committee on Hospital Care and Institute for Patient- and Family-Centered Care. Patient- and family-centered care and the pediatrician's role. Pediatrics 2012; 129:394-404.

5. Best advice - Social determinants of health. Mississauga (ON): College of Family Physicians of Canada; 2015. Available: https://patientsmedicalhome.ca/files/ uploads/BA_SocialD_ENG_WEB.pdf (accessed 2018 Dec. 11).

6. Pinto $A D$, Bloch $G$. Framework for building primary care capacity to address the social determinants of health. Can Fam Physician 2017;63:e476-82.

7. Billioux A, Verlander K, Anthony S, et al. Standardized screening for healthrelated social needs in clinical settings: the Accountable Health Communities screening tool [discussion paper]. In: NAM Perspectives. Washington (DC): National Academy of Medicine; 2017:1-9. doi: 10.31478/201705b. Available: https://nam.edu/wp-content/uploads/2017/05/Standardized-Screening-for-Health -Related-Social-Needs-in-Clinical-Settings.pdf (accessed 2018 Dec. 11).

8. Adler NE, Cutler DM, Fielding JE. Addressing social determinants of health and health disparities: a vital direction for health and health care [discussion paper]. In: NAM Perspectives. Washington (DC): National Academy of Medicine; 2016:1-16.

9. Giuse NB, Koonce TY, Kusnoor SV, et al. Institute of Medicine measures of social and behavioral determinants of health: a feasibility study. Am J Prev Med 2017;52:199-206.

10. Pan-Canadian dialogue to advance the measurement of equity in health care: proceedings report. Ottawa: Canadian Institute for Health Information; 2016.

11. Social determinants of health and health inequalities. Ottawa: Government of Canada; 2018. Available: www.phac-aspc.gc.ca/ph-sp/determinants/index -eng.php (accessed 2018 Dec. 11).

12. Closing the gap in a generation: health equity through action on the social determinants of health. Final report of the Commission on Social Determinants of Health. Geneva: World Health Organization; 2008. Available: http://apps.who.int/ iris/bitstream/10665/43943/1/9789241563703_eng.pdf (accessed 2018 Feb. 9).

13. Institute of Medicine (US) Board on the Health of Select Populations. Collecting sexual orientation and gender identity data in electronic health records: workshop summary. Washington (DC): National Academies Press (US); 2013.

14. Deutsch MB, Keatley J, Sevelius J, et al. Collection of gender identity data using electronic medical records: survey of current end-user practices. $J$ Assoc Nurses AIDS Care 2014;25:657-63.

15. Institute of Medicine (US) Committee on Lesbian. Gay, bisexual, and transgender health issues and research gaps and opportunities. The health of lesbian, gay, bisexual, and transgender people: building a foundation for better understanding. Washington (DC): National Academies Press (US); 2011.

16. Nguyen A, Lau BD. Collecting sexual orientation and gender identity information: filling the gaps in sexual and gender minority health. Med Care 2018;56:205-7.

17. Cruz TM. Assessing access to care for transgender and gender nonconforming people: a consideration of diversity in combating discrimination. Soc Sci Med 2014;110:65-73.

18. Progovac AM, Cook BL, Mullin BO, et al. Identifying gender minority patients' health and health care needs in administrative claims data. Health Aff (Millwood) 2018;37:413-20.

19. Abramovich A, Shelton J, editors. Where am I going to go? Intersectional approaches to ending LGBTQ2S youth homelessness in Canada \& the US. Toronto: The Canadian Observatory on Homelessness/Homeless Hub; 2017. Available: http://homelesshub.ca/whereamigoingtogo (accessed 2018 Dec. 11).

20. What is intersex? [home]. Rohnert Park (CA): Intersex Society of North America. Available: www.isna.org/faq/what_is_intersex (accessed 2018 Sept. 26).

21. GLAAD Media reference guide, 10th edition. GLAAD; 2016. Available: www. glaad.org/sites/default/files/GLAAD-Media-Reference-Guide-Tenth-Edition. pdf (accessed 2018 Sept. 26).

22. Media reference guide - Discussing trans- and gender-diverse people. Toronto: Rainbow Health Ontario; 2016. Available: www.rainbowhealthontario.ca/ wp-content/uploads/2016/01/Media-Reference-Guide-Trans-and-Gender-Diverse -People1.pdf (accessed 2018 Sept. 26).

23. Scheim Al, Bauer GR. Sex and gender diversity among transgender persons in Ontario, Canada: results from a respondent-driven sampling survey. J Sex Res 2015;52:1-14.

24. Bauer GR, Zong X, Scheim Al, et al. Factors impacting transgender patients' discomfort with their family physicians: a respondent-driven sampling survey. PLoS One 2015;10:e0145046. 
25. Bauer GR, Scheim AI, Deutsch MB, et al. Reported emergency department avoidance, use, and experiences of transgender persons in Ontario, Canada: results from a respondent-driven sampling survey. Ann Emerg Med 2014;63: 713-20.e1.

26. Tjepkema M. Health care use among gay, lesbian and bisexual Canadians. Health Rep 2008;19:53-64.

27. Bergeron S, Senn CY. Health care utilization in a sample of Canadian lesbian women: predictors of risk and resilience. Women Health 2003;37:19-35.

28. Cahill S, Singal R, Grasso C, et al. Do ask, do tell: High levels of acceptability by patients of routine collection of sexual orientation and gender identity data in four diverse American community health centers. PLoS One 2014; 9:e107104.

29. Tan DHS, Hull MW, Yoong D, et al.; Biomedical HIV Prevention Working Group of the CIHR Canadian HIV Trials Network. Canadian guideline on HIV pre-exposure prophylaxis and nonoccupational postexposure prophylaxis. CMAJ 2017;189: E1448-58.

30. In pursuit of health equity: defining stratifiers for measuring health inequality A focus on age, sex, gender, income, education and geographic location. Ottawa: Canadian Institute for Health Information; 2018.

31. Pinto AD, Glattstein-Young G, Mohamed A, et al. Building a foundation to reduce health inequities: routine collection of sociodemographic data in primary care. J Am Board Fam Med 2016;29:348-55.

32. We ask because we care: the Tri-Hospital + TPH health equity data collection research project report. Toronto: Toronto Public Health; St. Michael's Hospital; CAMH; Mount Sinai Hospital; 2013.

33. Kiran T, Davie S, Singh D, et al. Cancer screening rates for people who identify as transgender: a cross-sectional analysis of primary care data. Can Fam Physician. In press.
34. Willis GB, Artino AR Jr. What do our respondents think we're asking? Using cognitive interviewing to improve medical education surveys. J Grad Med Educ 2013;5:353-6.

35. Pope C, Ziebland S, Mays N. Qualitative research in health care. Analysing qualitative data. BMJ 2000;320:114-6.

36. Tourangeau R, Rips LJ, Rasinski K. The psychology of survey response. 1st ed Cambridge (UK): Cambridge University Press; 2000.

37. Bauer GR, Braimoh J, Scheim Al, et al. Transgender-inclusive measures of sex/ gender for population surveys: mixed-methods evaluation and recommendations. PLoS One 2017;12:e0178043.

38. Maragh-Bass AC, Torain M, Adler R, et al. Is it okay to ask: Transgender patient perspectives on sexual orientation and gender identity collection in healthcare. Acad Emerg Med 2017;24:655-67.

39. Haider AH, Schneider EB, Kodadek LM, et al. Emergency department query for patient-centered approaches to sexual orientation and gender identity: the EQUALITY study. JAMA Intern Med 2017;177:819-28.

40. Bjarnadottir RI, Bockting W, Dowding DW. Patient perspectives on answering questions about sexual orientation and gender identity: an integrative review. J Clin Nurs 2017;26:1814-33.

41. Brooks H, Llewellyn CD, Nadarzynski T, et al. Sexual orientation disclosure in health care: a systematic review. Br J Gen Pract 2018;68:e187-96.

42. Tate CC, Ledbetter JN, Youssef CP. A two-question method for assessing gender categories in the social and medical sciences. J Sex Res 2013;50:767-76.

43. Bosse JD, Leblanc RG, Jackman K, et al. Benefits of implementing and improving collection of sexual orientation and gender identity data in electronic health records. Comput Inform Nurs 2018;36:267-74.

44. Cahill SR, Baker K, Deutsch MB, et al. Inclusion of sexual orientation and gender identity in Stage 3 meaningful use guidelines: a huge step forward for LGBT health. LGBT Health 2016;3:100-2.
Competing interests: Andrew Pinto reports receiving personal fees from the University of Toronto, the Department of Family and Community Medicine at St. Michael's Hospital, and from the Li Ka Shing Knowledge Institute at St. Michael's Hospital and the Physicians' Services Incorporated Foundation, outside the submitted work. Kimberly Devotta reports receiving grants from the Toronto Central Local Health Integration Network, during the conduct of the study. Tara Kiran reports receiving personal fees from the Toronto Central Local Health Integration Network, the Department of Community and Family Medicine at St. Michael's Hospital and the University of Toronto, Health Quality Ontario and the Canadian Institutes of Health Research, outside the submitted work. At the time of the study, she was the Board Chair for the St. Michael's Hospital Academic Family Health Team. No other competing interests were declared.

This article has been peer reviewed.

Affiliations: The Upstream Lab (Pinto), Centre for Urban Health Solutions, Li Ka Shing Knowledge Institute and Department of Family and Community Medicine (Pinto, Kiran), St. Michael's Hospital; Department of Family and Community Medicine (Pinto, Kiran), Faculty of Medicine and Dalla Lana School of Public Health (Pinto, Abramovich, Nisenbaum), University of Toronto; Centre for Urban Health Solutions (Aratangy, Devotta, Nisenbaum, Wang, Kiran), Li Ka Shing Knowledge Institute, St. Michael's Hospital; Institute for Mental Health Policy Research (Abramovich), Centre for Addiction and Mental Health; Health Quality Ontario (Kiran), Toronto, Ont.
Contributors: Andrew Pinto and Tara Kiran contributed to the overall conception and design of the work. Andrew Pinto, Tatiana Aratangy, Kim Devotta, Rosane Nisenbaum and Tara Kiran assisted with the plans for data collection. Kim Devotta assisted with qualitative data collection. All authors assisted with plans for data analysis, with Tatiana Aratangy and Kim Devotta contributing substantially to the qualitative data analysis and Rosane Nisenbaum and Ri Wang contributing substantially to the quantitative data analysis. Andrew Pinto drafted the manuscript. All of the authors revised it critically for important intellectual content, gave final approval of the version to be published and agreed to be accountable for all aspects of the work.

Funding: This study was supported by a grant from the Toronto Central Local Health Integration Network. The funder played no role in data collection or data analysis, or the writing and editing of this paper. Andrew Pinto and Tara Kiran are supported as Clinician Scientists by the Department of Family and Community Medicine, Faculty of Medicine at the University of Toronto and at St. Michael's Hospital, and by the Li Ka Shing Knowledge Institute, St. Michael's Hospital. Dr. Pinto is also supported by a fellowship from the Physicians' Services Incorporated Foundation. Dr. Kiran is the Fidani Chair in Improvement and Innovation at the University of Toronto. She is also supported by the Canadian Institutes of Health Research and Health Quality Ontario as an Embedded Clinician Researcher. The opinions, results and conclusions reported in this article are those of the authors and are independent from any funding sources.
Data sharing: Researchers interested in accessing the data set used in this study may contact the corresponding author.

Acknowledgements: The authors thank Lisa Miller for her help with extracting data from our electronic medical record and Andree Schuler for assistance with data analysis. We thank Rebecca Brown and Cheryl Pedersen from the Survey Research Unit at the Centre for Urban Health Solutions, St. Michael's Hospital, for assistance with conducting interviews and focus groups and assisting with the qualitative analysis. We thank Anne Rucchetto for assistance with editing this paper. The study team appreciates the involvement of the following individuals on its Advisory Group: Caroline Bennett-AbuAyyash (Mount Sinai Hospital), Jane Cooney, Cynthia Damba (Toronto Central Local Health Integration Network), Gail Dobell (Health Quality Ontario), Katherine Henning (University Health Network), Bernadee Koh-Bilodeau (Health Quality Ontario), Bev Leaver (Stonegate Community Health Centre), Carol Mulder (Association of Family Health Teams of Ontario), Cathy O'Neill (St. Michael's Hospital), Erin Pichora (Canadian Institute for Health Information) and Marjeiry Robinson. This report does not necessarily represent the views of members of the advisory group, or the official view or position of any organization represented by members of the study team or advisory group.

Accepted: Dec. 12, 2018

Correspondence to: Andrew Pinto, andrew.pinto@utoronto.ca 